TOWARDS A RELATIONALLY-ORIENTATED APPROACH TO THERAPY:

EMPIRICAL SUPPORT AND ANALYSIS

\author{
MICK COOPER
}

COUNSELLING UNIT, UNIVERSITY OF STRATHCLYDE, GLASGOW (MICK.COOPER@STRATH.AC.UK)

PUBLISHED IN:

BRITISH JOURNAL OF GUIDANCE AND COUNSELLING, 32(4), 451-461. 2004. 
TOWARDS A RELATIONALLY-ORIENTATED APPROACH TO

THERAPY: EMPIRICAL SUPPORT AND ANALYSIS 


\begin{abstract}
Drawing on contemporary evidence in the counselling and psychotherapy research field, this paper argues that there is growing support for a relationship-orientated approach to therapeutic practice. The paper reviews findings from a range of meta-analytical and individual studies which provide strong evidence for the centrality of relational factors to the successfulness of therapy, and then goes on to examine the specific variables that appear to be linked to positive therapeutic change. Having considered some of the empirical evidence that challenges this position and highlighted the importance of individual differences, the paper concludes by arguing that we need to develop and expand our understanding of the kind of relational factors and processes that most facilitate therapeutic change.
\end{abstract}

\title{
Introduction
}

In recent years, the field of counselling and psychotherapy has witnessed a surge of interest in relational approaches to therapy: approaches which in which the therapeutic process is held to rely most heavily on the quality and mutual experience of the client-therapist relationship rather than on any particular set of techniques (Magnavita, 2000b). Not only have several new relational therapies been established - such as Friedman's (1985) 'Dialogic Psychotherapy’, Magnavita’s (2000b) 'relational therapy', and DeYoung's (2003) 'Relational Psychotherapy' - but relationally-orientated variants of many of the key therapeutic approaches have started to emerge. In the field of psychodynamic therapy, for instance, there is the intersubjective therapy of Stolorow and his colleagues (e.g. Stolorow et al., 1987); Hycner has developed a dialogicallyorientated approach to gestalt therapy (Hycner \& Jacobs, 1995); and a relational perspective on transactional analysis has been proposed (Hargaden \& Sills, 2002). Even those approaches that are traditionally relationship-orientated, such as person-centred and existential therapies, have witnessed the emergence of more intersubjective and dialogic perspectives (e.g. Bohart \& Byock, 2003; Schmid, 2002; Spinelli, 1997). Feminist therapists, drawing on Kohut and other 
psychodynamic thinkers, have also developed a strongly relational approach to therapy (e.g. Jordan, 1991, 2000), as well as a relational theory of human - and particularly women's development (e.g. Surrey, 1991). Recent years have also witnessed advances in relational forms of clinical diagnosis (Magnavita, 2000a; Rigazio-DiGilio, 2000), extending systemic and interpersonal thinking into the field of individual, clinical treatment.

To a great extent, these developments may be a product of the changing intellectual zeitgeist. In the field of philosophy, for instance, postmodern thinking has come to fundamentally challenge the assumption that human beings are independent and autonomous organisms, proposing, instead, that we are fundamentally and inextricably inter-twined with others in our world (Baudrillard, 1993; Gergen, 1999). Late twentieth century feminist and trans-cultural thinkers have also called into question the notion of individual, discrete selves; arguing that this conception of human being is more a product of western, male interests than a universal and unchallengeable truth (Holdstock, 1993; Jordan et al., 1991). Support for a relational view of therapy, however, does not only come from the sphere of theoretical developments. Rather, in recent years, empirical evidence in the counselling and psychotherapy research field has been increasingly pointing to the importance of the relationship to the therapeutic work, and it is this body of evidence that this paper will primarily focus upon.

\section{Therapeutic relationships and therapeutic outcome}

In 1999, An American Psychological Association Division of Psychotherapy Task Force was commissioned to 'identify, operationalize, and disseminate information on evidence-based therapy relationships' (Norcross, 2002a, p.6). Consisting of many of the leading figures in the psychotherapy research field (such as Larry Beutler, Adam Hovarth and Clara Hill), it conducted the largest ever review of research on the therapeutic relationship, and its distillation of the 
evidence comes to over 400 pages (Norcross, 2002b). Its main conclusion was that 'The therapy relationship...makes substantial and consistent contributions to psychotherapy outcome independent of the specific type of treatment (Steering Committee, 2002, p.441) (the "therapy relationship' is defined here as, 'the feelings and attitudes that therapist and client have towards one another, and the manner in which these are expressed' (Norcross, 2002a, p.7)). It also concluded that, 'Practice and treatment guidelines should explicitly address therapist behaviours and qualities that promote a facilitative therapy relationship' (Steering Committee, 2002, p.441) and that, 'Efforts to promulgate practice guidelines or evidence-based lists of effective psychotherapy without including the therapy relationship are seriously incomplete and potentially misleading on both clinical and empirical grounds' (Steering Committee, 2002, p.441). The report went on to recommend that practitioners should, 'make the creation and cultivation of a therapy relationship...a primary aim in the treatment of patients' (Steering Committee, 2002, p.442), and that therapeutic training programs should 'provide explicit and competency-based training in the effective elements of the therapy relationship' (Steering Committee, 2002, p.442).

As an example of the kind of study that this review drew on: Krupnick and colleagues (1996) examined the relationship between therapeutic alliance and outcome for 225 depressed clients who had been randomly distributed between four treatment groups: cognitive behaviour therapy; interpersonal psychotherapy; pharmacotherapy and clinical management; and placebo plus clinical management. This data came from one of the largest and most rigorous studies of therapeutic outcome: the National Institute of Mental Health (NIMH) Treatment of Depression Collaborative Research Program. Researchers had previously found no significant differences in outcome between the cognitive-behavioural and interpersonal forms of therapeutic treatment (Elkin et al., 1989), but what Krupnick et al. did find was a strong positive correlation between the quality of the therapeutic alliance - as rated by the clients - and improvements in clinical outcome. 
Perhaps one of the most surprising findings that came out of this study was that the relationship between the quality of the therapeutic alliance and clinical outcomes tended to be as strong in the cognitive-behavioural condition as it was in the interpersonal therapy one (and, indeed, in the pharmacotherapy and placebo conditions, too) (Krupnick et al., 1996). In other words, as the APA Task Force suggests, the quality of the therapeutic relationship would seem to relate to clinical outcome, even when the particular form of therapy being practiced is not an explicitly relational one. Other findings bear out this conclusion (see Keijsers et al., 2000). In investigating a behavioural self-control training program for problem drinkers, for instance, Miller (1980) found a strong correlation between positive outcomes and therapists' levels of empathy, as rated by external observers. Summarising the evidence with respect to cognitive-behavioural treatments, Keijsers et al. write that, 'there is conclusive empirical evidence' to suggest that the Rogerian therapist variables - empathy, nonpossessive warmth, positive regard and genuineness have a consistent impact on treatment results across a variety of patients; and that, for the concept of the therapeutic alliance, 'fairly stable associations with treatment results have been found' (2000, p.285).

Indeed, there is some evidence to suggest that relational variables may of greater importance in the non-explicitly relational therapies than in the relational ones. Based on a meta-analysis of all the relevant studies, for instance, Bohart et al. (2002) found that the relationship between therapists' empathy and clinical outcomes was substantially higher for cognitive-behavioural therapies than it was for psychodynamic and experiential/humanistic ones.

More controversially, it could be argued that the primary vehicle for therapeutic change in the more instrumental therapies is not, as is often supposed, the therapists' techniques or strategies, but the quality of the therapeutic relationship. In reviewing those five studies, for instance, that 
asked clients what they felt had been the most helpful aspect of their cognitive-behavioural treatment, Keijsers et al. (2000) state that all, 'consistently reported that patients had found the relationship with their therapist more helpful than the cognitive-behavioural techniques that were employed. Furthermore,' they write, 'high helpfulness ratings for relationship variables tended to be associated with better treatment outcomes... whereas high helpfulness ratings for cognitivebehavioural techniques were not' (2000, p.267). Keijsers et al. go on to state that, 'when patients who have completed cognitive-behavioural treatments are asked to indicate what had helped them to overcome their problems, they will answer, "talking with someone who listens and understands"” (2000, p.291). Such findings are backed up by more 'objective' evidence. Castonguay et al. (1996), for instance, looked at data from 64 clients being treated for depression with cognitive therapy. As with many other studies, they found that the therapeutic alliance was significantly related to clients' improvements in terms of depressive symptoms and global functioning. Of more interest, however, was their finding that a negative correlation existed between clinical improvements and the therapists' use of a particular cognitive-behavioural strategy: 'reflecting intrapersonal consequences' (e.g. interventions such as 'When you think of yourself as a failure, you become depressed'). Again, then, this suggests that a cognitivebehavioural therapists' relational abilities may be a more important factor in bringing about clinical change than their use of particular therapeutic techniques.

Such hypotheses are supported by the evidence and arguments emerging from 'common factors' models of therapeutic change - an approach which is rapidly gaining ground in the psychotherapeutic research field (e.g. Hubble et al., 1999; M. J. Lambert, 1992). Advocates of this approach argue that therapeutic change is not, primarily, a result of specific techniques being applied by practitioners of specific schools. Rather, they argued that there are a common set of factors, or ingredients, that underlie all therapeutic change, whatever the therapeutic modality being practiced. Asay and Lambert (1999), drawing on Lambert (1992), suggest that the most 
significant common factor, in terms of a positive therapeutic outcome, is 'client variables and extratherapeutic events': such as the client's level of motivation and their life circumstances during therapy. Based on an extensive meta-analysis of the data, they calculate that this factor accounts for approximately 40 percent of the variance in therapeutic change. But closely behind this factor, and, again, based on an extensive meta-analysis of the data, are relationship variables: such as the therapist's level of empathy and their willingness to give the client feedback (see Norcross, 2002b). This factor, they calculate, accounts for approximately 30 percent of the variance in therapeutic outcome. Expectancy and placebo effects are then calculated to account for fifteen percent of the variance in outcome, as are specific technique and model factors. These common factor models suggest, then, that 'Except what the client brings to therapy, [relationship factors] are probably responsible for most of the gains resulting from psychotherapy interventions' (Hubble et al., 1999, p.9).

\section{Key relational factors}

So what are the relational factors that seem to play such a central role in successful therapeutic outcomes? The APA Division of Psychotherapy Task Force concluded that three relational variables (with respect to individual therapy) were 'demonstrably effective' (Steering Committee, 2002). The first of these was the therapeutic alliance. This term has been used in the literature in several different ways and refers to a number of related constructs, but can be generally thought of as the "quality and strength of the collaborative relationship between client and therapist in therapy' (Hovarth \& Bedi, 2002, p.41). Bordin (1994), in some of the most influential work on the therapeutic alliance, has broken this concept down into three main components: agreement on the therapeutic goals, consensus on the tasks that make up therapy, and the bond between client and therapist. Evidence suggests that establishing a strong alliance early on in the therapeutic relationship is particularly important, and alliance measured between the third and fifth session 
has proven to be a consistent predictor of final therapy outcome (Hovarth \& Bedi, 2002). A second relational variable found to be demonstrably effective was that of 'goal consensus and collaboration', which overlaps quite considerably with the concept of the therapeutic alliance. This, however, refers specifically to the therapist-client agreement on therapy goals and expectations, and the mutual working together of these two parties in the helping relationship. Interestingly, whilst this is one of the lesser known and researched relational variables, it was also rated as having the highest association with therapeutic outcome by a panel of experts reviewing the empirical evidence (Norcross, 2002b). The third relational variable in individual therapy that was found to be demonstrably effective was that of empathy.

The APA Division of Psychotherapy Task Force also concluded that seven relational variables were 'promising and probably effective' (Steering Committee, 2002). The first two of these, positive regard and congruence/genuineness, are well known Rogerian core conditions (Rogers, 1957). The third, feedback, is a less examined variable, and refers to the process of providing clients with information about the way that they, or their behaviours, are perceived or experienced. Repairing alliance ruptures is a fourth variable found to be promising and probably effective, and refers to the therapist's willingness to address tensions or breakdowns in the collaborative relationship between themselves and their client. Self-disclosure - therapist statements that reveal something personal about themselves (Hill \& Knox, 2002) - was also found to be promising and probably effective, though the researchers concluded that such disclosures should be infrequent, and that disclosures on certain topics (such as professional background) were much more appropriate than disclosures on others (such as sexual practices and beliefs). A similar conclusion was reached with respect to 'quality of relational interpretations': that, whilst it was considered a promising and probably effective element of the therapeutic relationship, it was concluded that interpretations should focus primarily on the central interpersonal themes for each client - i.e. feedback on their way of being with another - and 
'high levels of transference interpretations should be avoided' (Crits-Christoph \& Gibbons, 2002, p.298). The final element of the therapeutic relationship that was found to be promising and probably effective was the therapist's 'management of countertransference': that is, their willingness and ability not to act out towards their clients.

Based on the empirical evidence, then, at the most general level, it would seem that the ideal therapeutic relationship is one in which therapist and client work together in a collaborative and open way; and in which the therapist is empathic, warm, affirming, and engaging: willing to communicate to the client how he or she perceives or experiences him or her, but able to do this in a sensitive, timely and positively-framed way, and able to bracket off his or her own biases and personal agendas. And, what the evidence suggests is that, if such a relationship is in place, it can make a sizeable - if not the most sizeable - contribution to the likelihood of a positive therapeutic outcome.

\section{Challenges to a relational emphasis}

It should be noted here, however, that not all researchers within the counselling and psychotherapy field agree. Indeed, within the person-centred field, itself, Sachse (2003) has argued that evidence from process-outcome research (see Sachse \& Eliot, 2002) points towards a therapeutic practice in which deliberate interventions and therapeutic strategies should dominate, and in which the traditional Rogerian conception of non-directive, relationally-orientated therapy should be abandoned. Even advocates of the common factors approach have acknowledged that, with some disorders, certain techniques have been proven to be optimally effective: specifically, exposure for anxiety disorders and behavioural treatments for sexual dysfunctions (Ogles et al., 1999). Statistical calculations by advocates of relationally-orientated and common factor models of therapy have also been questioned. Beutler et al. (2004), for instance, writing in the most 
authoritative of psychotherapy research handbooks - Bergin and Garfield's Handbook of Psychotherapy and Behaviour Change (Michael J Lambert, 2004) - state that, 'The collection of meta-analytic findings over the past 10 years indicate that relationship quality accounts for a far more modest proportion of the variance in outcome than the 30\% suggested by Lambert' (2004, p.282). Re-analysing the data, they go on to suggest that the therapeutic relationship probably accounts for somewhere between seven percent and seventeen percent of the variance in outcomes. Nevertheless, they still conclude that, 'there can be no doubt that relationship quality is one of the stronger correlates of outcome' (2004, p.292).

\section{Client factors}

It would seem, then, that there is general agreement within the counselling and psychotherapy research field that the relationship does play a significant role in facilitating positive therapeutic change, though its degree of importance is a matter of on-going debate. Recent years, however, have witnessed a move away from attempts to establish the exact amount by which the therapeutic relationship impacts all therapeutic work, towards an increasing acknowledgement that the importance of the therapeutic relationship may vary greatly from client to client (Beutler et al., 2004; Norcross, 2002b). A client who has felt isolated throughout her life, for instance, may be much more responsive to a warm and accepting therapeutic relationship than a client who has many close friends, but desperately wants some practical advice on how to sort out her problems. Such a position is strongly supported by the empirical research. Blatt et al. (1996), for instance, found that the relationship between clinical outcomes and the therapeutic relationship was significantly mediated by a client's level of perfectionism. Specifically: whilst the quality of the therapeutic relationship was significantly predictive of therapeutic gain for clients who had moderate levels of perfectionism, it was only marginally predictive of therapeutic gain for clients who had low or high levels of perfectionism. Blatt et al. account for this by suggesting that the 
problems that low-perfectionist clients bring to therapy are unlikely to revolve around negative views of self or other (having a low actual-ideal discrepancy), and therefore they are less likely to be responsive to such relational qualities as unconditional positive regard. On the other hand, they suggest that clients high in perfectionism are unlikely to benefit extensively from therapy, such that the quality of the relationship is not likely to make much difference to their outcomes. Along similar lines, Bohart et al. (2002) report empirical evidence which suggests that 'patients who are highly sensitive, suspicious, poorly motivated, and reactive against authority perform relatively poorly with therapists who are particularly empathic, involved and accepting' (2002, p.100). Such clients, they suggest, might prefer more business-like therapists.

It is not only the case, then, that different clients may be impacted by the therapeutic relationship to different degrees, but that different clients may need very different types of therapeutic relationships. Indeed, in the report of the APA Division of Psychotherapy Task Force (Norcross, 2002b), much attention was paid to the kind of variables - such as levels of resistance and functional impairment - that mediate and moderate the impact of the client-therapist relationship, and require the therapist to customise the particular type of therapeutic engagement offered to the client for optimal outcomes.

\section{Conclusion}

Increasingly, then, the empirical evidence seems to indicate that an empathic, warm, collaborative and engaging therapeutic relationship contributes to positive therapeutic outcomes in the majority of clients, although different clients seem to have different relational needs. Such a conclusion does not, in any way, suggest that particular therapeutic techniques are irrelevant to the success of the therapeutic work, but it does suggest that they need to be embedded in, or combined with, a positive therapeutic encounter. It also suggests that, as well as developing new techniques and 
therapeutic strategies, we should be attempting to deepen our understanding of the therapeutic relationship, and the different qualities and characteristics that may facilitate different clients' therapeutic growth. In many respects, our understanding of the key components of a facilitative therapeutic relationship have progressed little since Rogers' seminal work on the necessary and sufficient conditions for therapeutic personality change (Rogers, 1957), and it would seem incumbent on us to develop and expand this horizon, as the newly-emerging relational approaches to therapy are attempting to do. With the introduction of new concepts like 'relational depth' (Mearns, 1997) and 'acknowledgement' (Schmid, 2002), there is a hope that we can move further and further into the heart of the kind of relationship that is healing for so many clients; furthering our understanding of a therapeutic variable that is already proven to be one of the most important factors in the success of the therapeutic work. 


\section{References}

Asay, T. P., \& Lambert, M. J. (1999). Therapist relational variables. In D. J. Cain \& J. Seeman (Eds.), Humanistic Psychotherapies: Handbook of Theory and Practice (pp. 531-557). Washington, DC: American Psychological Association.

Baudrillard, J. (1993). Symbolic Exchange and Death (I. H. Grant, Trans.). London: Sage.

Beutler, L. E., Malik, M., Alimohamed, S., Harwood, M. T., Talebi, H., Noble, S., et al. (2004). Therapist Variables. In M. J. Lambert (Ed.), Bergin and Garfield's Handbook of Psychotherapy and Behaviour Change (5th ed., pp. 227-306). Chicago: John Wiley and Sons.

Blatt, S. J., Zuroff, D. C., Quinlan, D. M., \& Pilkonis, P. A. (1996). Interpersonal factors in brief treatment of depression: Further analyses of the national institute of mental health treatment of depression collaborative research program. Journal of Consulting and Clinical Psychology, 64(1), 162-171.

Bohart, A. C., \& Byock, G. (2003). How does empathy facilitate? Paper presented at the World Conference for Person-Centred and Experiential Psychotherapy and Counselling, Egmond am Zee.

Bohart, A. C., Elliott, R., Greenberg, L. S., \& Watson, J. C. (2002). Empathy. In J. C. Norcross (Ed.), Psychotherapy Relationships that Work: Therapist Contributions and Responsiveness to Patients (pp. 89-108). Oxford: Oxford University Press.

Bordin, E. S. (1994). Theory and research on the therapeutic working alliance: New Directions. In A. O. Hovarth \& L. S. Greenberg (Eds.), The Working Alliance: Theory, Research and Practice. New York: Wiley.

Castonguay, L. G., Goldfried, M. R., Wiser, S., Raue, P. J., \& Hayes, A. M. (1996). Predicting the effect of cognitive therapy for depression: A study of unique and common factors. Journal of Consulting and Clinical Psychology, 64(3), 497-504. 
Crits-Christoph, P., \& Gibbons, M. B. C. (2002). Relational Interpretations. In J. C. Norcross (Ed.), Psychotherapy Relationships that Work: Therapist Contributions and Responsiveness to Patients (pp. 285-300). Oxford: Oxford University Press.

DeYoung, P. A. (2003). Relational Psychotherapy: A Primer. New York: Brunner Routledge.

Elkin, I., Shea, M. T., Watkins, J. T., Imber, S. D., Sotsky, S. M., Collins, J. F., et al. (1989). National-Institute-of-Mental-Health Treatment of Depression Collaborative ResearchProgram - General Effectiveness of Treatments. Archives of General Psychiatry, 46(11), 971-982.

Friedman, M. (1985). The Healing Dialogue in Psychotherapy. New York: Jason Aronson, Inc. Gergen, K. (1999). An Invitation to Social Construction. London: Sage.

Hargaden, H., \& Sills, C. (2002). Transactional Analysis in Psychotherapy: A Relational Perspective. London: Routledge.

Hill, C. E., \& Knox, S. (2002). Self-disclosure. In J. C. Norcross (Ed.), Psychotherapy Relationships that Work: Therapist Contributions and Responsiveness to Patients (pp. 255-265). Oxford: Oxford University Press.

Holdstock, L. (1993). Can we afford not to revision the person-centred concept of self? In D. Brazier (Ed.), Beyond Carl Rogers. London: Constable.

Hovarth, A. O., \& Bedi, R. P. (2002). The alliance. In J. C. Norcross (Ed.), Psychotherapy Relationships that Work: Therapist Contributions and Responsiveness to Patients (pp. 37-69). Oxford: Oxford University Press.

Hubble, M., Duncan, B. L., \& Miller, S. D. (1999). The Heart and Soul of Change: What Works in Therapy. Washington, DC: American Psychological Association.

Hycner, R., \& Jacobs, L. (1995). The Healing Relationship in Gestalt Therapy. Highland, NY: Gestalt Journal Publications.

Jordan, J. V. (1991). Empathy, mutuality and therapeutic change: Clinical implications of a relational model. In J. V. Jordan, A. G. Kaplan, J. B. Miller, I. P. Stiver \& J. L. Surrey 
(Eds.), Women's Growth in Connection: Writings from the Stone Centre (pp. 283-289).

New York: The Guilford Press.

Jordan, J. V. (2000). The role of mutual empathy in relational/cultural therapy. Journal of Clinical Psychology, 56(8), 1005-1016.

Jordan, J. V., Surrey, J. L., \& Kaplan, A. G. (1991). Women and empathy: Implications for psychological development and psychotherapy. In J. V. Jordan, A. G. Kaplan, J. B.

Miller, I. P. Stiver \& J. L. Surrey (Eds.), Women's Growth in Connection: Writings from the Stone Centre (pp. 27-50). New York: The Guilford Press.

Keijsers, G. P. J., Schaap, C. P. D. R., \& Hoogduin, C. A. L. (2000). The impact of interpersonal patient and therapist behaviour on outcome in cognitive-behavior therapy. Behaviour Modification, 24(2), 264-297.

Krupnick, J. L., Sotsky, S. M., Simmens, S., Moyer, J., Elkin, I., Watkins, J., et al. (1996). The role of the therapeutic alliance in psychotherapy and pharmacotherapy outcome: Findings in the national institute of mental health treatment of depression collaborative research program. Journal of Consulting and Clinical Psychology, 64(3), 532-539.

Lambert, M. J. (1992). Implications of outcome research for psychotherapy integration. In J. C. Norcross \& M. R. Goldstein (Eds.), Handbook of Psychotherapy Integration (pp. 94129). New York: Basic Books.

Lambert, M. J. (Ed.). (2004). Bergin and Garfield's Handbook of Psychotherapy and Behaviour Change (5th ed.). Chicago: John Wiley and Sons.

Magnavita, J. J. (2000a). Integrative relational therapy of complex clinical syndromes: Ending the multigenerational transmission process. Journal of Clinical Psychology, 56(8), 10511064.

Magnavita, J. J. (2000b). Introduction: The growth of relational therapy. Journal of Clinical Psychology, 56(8), 999-1004.

Mearns, D. (1997). Person-Centred Counselling Training. London: Sage. 
Miller, W. R., Taylor, C. A., \& West, J. C. (1980). Focused versus broad-spectrum behaviour therapy for problem drinkers. Journal of Consulting and Clinical Psychology, 48(5), 590601.

Norcross, J. C. (2002a). Empirically supported therapy relationships. In J. C. Norcross (Ed.), Psychotherapy Relationships that Work: Therapist Contributions and Responsiveness to Patients (pp. 3-16). Oxford: Oxford University Press.

Norcross, J. C. (Ed.). (2002b). Psychotherapy Relationships that Work: Therapists Contributions and Responsiveness to Patients. New York: Oxford University Press.

Ogles, B. M., Anderson, T., \& Lunnen, K. M. (1999). The contribution of models and techniques to therapeutic efficacy: contradictions between professional trends and clinical research. In M. Hubble, B. L. Duncan \& S. D. Miller (Eds.), The Heart and Soul of Change: What Works in Therapy (pp. 201-225). Washington, DC: American Psychological Association.

Rigazio-DiGilio, S. A. (2000). Relational diagnosis: A coconstructive-developmental perspective on assessment and treatment. Journal of Clinical Psychology, 56(8), 1017-1036.

Rogers, C. R. (1957). The necessary and sufficient conditions of therapeutic personality change. Journal of Consulting Psychology, 21(2), 95-103.

Sachse, R. (2003). Necessary Changes to the Process Concept of CCT. Paper presented at the 6th World Conference on Person-Centered and Experiential Psychotherapy and Counselling, Egmond am Zee, The Netherlands.

Sachse, R., \& Eliot, R. (2002). Process-outcome research on humanistic therapy variables. In D. J. Cain \& J. Seeman (Eds.), Humanistic Psychotherapies: Handbook of Research and Practice. Washington, DC: American Psychological Association.

Schmid, P. F. (2002). Knowledge of acknowledgement? Psychotherapy as 'the art of notknowing' - prospects on further developments of a radical paradigm. Person-Centred and Experiential Psychotherapies, 1(1\&2), 56-70. 
Spinelli, E. (1997). Tales of Un-Knowing: Therapeutic Encounters from an Existential Perspective. London: Duckworth.

Steering Committee. (2002). Empirically supported therapy relationships: Conclusions and recommendations on the Division 29 task force. In J. C. Norcross (Ed.), Psychotherapy Relationships that Work: Therapist Contributions and Responsiveness to Patients (pp. 441-443). Oxford: Oxford University Press.

Stolorow, R. D., Brandchaft, B., \& Atwood, G. E. (1987). Psychoanalytic Treatment: An Intersubjective Approach. Hillsdale, NJ: The Analytic Press.

Surrey, J. L. (1991). The self-in-relation: A theory of women's development. In J. V. Jordan, A. G. Kaplan, J. B. Miller, I. P. Stiver \& J. L. Surrey (Eds.), Women's Growth in Connection: Writings from the Stone Centre (pp. 51-66). New York: The Guilford Press. 